\title{
BEES SUBSTITUTE BIRDS IN POLLINATION OF ORNITOGAMOUS CLIMBER CAMPSIS RADICANS (L.) SEEM. IN POLAND
}

\author{
IWONA KOŁODZIEJSKA-DEGÓRSKA, MARCIN ZYCH \\ Warsaw University Botanic Garden \\ Aleje Ujazdowskie 4, 00-478 Warszawa, Poland \\ e-mail: iwonak@biol.uw.edu.pl
}

(Received: June 15, 2005. Accepted: September 29, 2005)

\begin{abstract}
Campsis radicans is an attractive climber with typical ornitogamous flowers, native to North America. In natural conditions this out-crossed plant is pollinated mostly by hummingbirds. In Poland, where C. radicans is cultivated as ornamental, it rarely sets seeds. The questions addressed in the present study were: (1) What animals pollinate its flowers in Poland?, and (2) What is the reason for infrequent fruit set? Field studies conducted in five localities in Poland showed that the principal pollinator is Apis mellifera, and the lack of seeds is usually caused by pollinator limitation or absence of genetically different pollen donor plants.
\end{abstract}

KEY WORDS: Campsis radicans, pollination, ornitogamy, pollinator shift, Apis mellifera.

\section{INTRODUCTION}

A simple classification of "pollination syndromes" (Faegri and van der Pijl 1979) was constructed for convenience in describing the complexity of pollination systems of angiosperms and recognizing traits that are usually over-represented in plants attractive to specific types of pollinators. Although intended to assist the researches, it soon was adopted by many as a complete typological system used to invoke the pollinators based solely on flower morphology instead of conducting time-consuming studies (Pellmyr 2002).

One of the most cited syndromes is that of hummingbird-pollinated plants with red, scentless, tubular flowers and no landing platform for animals (Raven 1972; Proctor et al. 1996). Flowers of that kind are produced by a well known climber trumpet creeper ( $C$. radicans, Bignoniaceae), native to south-eastern United States, and regarded as one of the most troublesome weeds in cotton and soybean in USA (Dowler 1998). In fact, in its natural environment, open woodlands and forest edges, flowers of $C$. radicans are pollinated by ruby-throated hummingbirds (Archilochus colubris). However, in more open habitats the plant is also visited by honey bees and bumblebees which may pollinate its flowers (Bertin 1982). This kind of habitats prevails for present day populations of trumpet creeper - it is frequently encountered in disturbed sites: railway embankments, fencerows, overgrown fields (Bertin 1982; Chachalis and Reddy 2000).
In Europe and in Poland C. radicans is regarded as an attractive ornamental and it is often planted in private gardens. For many years the distribution of the trumpet creeper in Poland was mainly constrained to specialist botanic gardens and arboreta and the plant was observed to produced seeds quite infrequently, however for the last several years it has been available from numerous nurseries (Polish Nurserymen Association 2004) and often introduced as a garden novelty in many regions of the country. From earlier studies on $C$. radicans it is known that the species is generally self-incompatible, however in case of mixed self and outcrossed pollen loads pollination with self pollen may take place (so called cryptic self fertility; Bertin and Sullivan 1988; Bertin et al. 1989).

Although usually less than $10 \%$ of flowers produce mature seeds (Bertin 1982), C. radicans is quite a prolific species in terms of seed production. Individual plants may produce up to 2800 viable wind-dispersed seeds (Chachalis and Reddy 2000). Other ecological and biological features regarded as determinats of successful invaders: climbing habit, ruderal life strategy, low seed mass etc. (Daehler 1998; Rejmánek and Richardson 1996) indicate its potentially invasive character and make $C$. radicans an interesting object to further observations in Europe and in Poland.

The questions addressed in the present study were: (1) What animal taxa pollinate flowers of $C$. radicans in Poland?, and (2) Is the plant pollinator limited or the paucity of fruits is the result of scarce distribution of individuals or not sufficient pollen loads carried by flower visitors? 


\section{MATERIAL AND METHODS}

\section{Campsis radicans (L.) Seem. (Bignoniaceae)}

Trumpet creeper is a woody climber, in its natural habitat flowering from June till September. Orange-red scentless tubular flowers are clustered in inflorescences consisting of up to 14 flowers. Orange calyces are flashy and persistent. Tubular corollas terminate in five lobes (Bertin 1982). Flowers are protandrous with five stamens (only four of them fully developed) and one style terminating in bilobate stigma (Vines 1960). Nectar production is high as compared to other Bignoniaceae species. Two types of nectaries (nuptial and extranuptial) produce nectar containing approx. 20\% sucrose and more glucose than fructose. Nectar from extranuptial nectaries contains also aminoacids (Galetto 1995). C. radicans is pollinated mainly by ruby-throat hummingbirds (Archilochus colubris, Trochilidae). It is visited also by honey bees (Apis mellifera L.) and various species of bumblebees (Bombus spp.) (Bertin 1982).

Transversely thin-winged seeds are enclosed in fruit capsule splitting at maturity (Vines 1960). In Poland trumpet creeper rarely sets fruit (M. Zych, pers. obser.).

\section{Study sites}

Observation of insect visitors were performed in five localities in Poland - three sites were situated in Central Poland (two in Warsaw and one in Józefosław), one site in south-western Poland (Wrocław) and one in western Poland (Kórnik near Poznań). Detailed descriptions of study sites and dates of observation are given in Table 1.

\section{Field observations}

There are no data on $C$. radicans pollination in Europe, it was therefore important to determine precisely the taxonomic affiliation of flower-visiting insects. Diurnal observations were carried out during summers 2001 and 2002, according to the following scheme: we randomly chose one inflorescence and for 20 minutes captured all insect-visitors. We performed 12 observation rounds per day, starting from 8.30 (first round) until 19.30 (last round).
Once selected, the inflorescence was not excluded from the next rounds, it was therefore possible that the same inflorescence was observed two or more times. Flowers that were out of reach from the ground (ladder, roof or building windows) were excluded from observation. In WR and WA1 we also investigated the activity of crepuscular insects. Observations were carried out from 20.30 till 23.30.

In case of rain or strong wind the observations were interrupted and the, missing rounds were performed on the following days. Insects were captured with an entomological net, killed with ethyl acetate, and stored pinned dry for further analyses of their pollen loads.

\section{Pollen load analyses}

For the investigation of pollen loads carried by insects visiting flowers of $C$. radicans, the modified method of Grace and Nelson (1981) and Lindsey (1984) was used (Zych 2002). Pollen grains from insect bodies were removed with a thin brush on a microscopic slide. This was done under a stereoscopic microscope until no further pollen was visible. The pollen was then stained with a drop of acetoorceine and covered with microscope-covering glass. Pollen samples were analysed under a light microscope. The brush was carefully cleaned of each insect after the examination, so as not to allow the pollen to contaminate the next sample.

\section{Importance of insect visitors}

The importance of insect taxon $\mathrm{x}$ (Ix) was calculated according to the equation:

$$
\mathrm{Ix}=\mathrm{PL} \times \mathrm{V}[\text { Equation 1] }
$$

Where:

$\mathrm{PL}$ - the average pollen load carried by an individual of a given insect species,

$\mathrm{V}$ - the average number of visits of insects of a given species during 12 hours of observation.

All I values for one study site in one year were summed up. These sums were treated as $100 \%$ and used for comparing the importance of insect taxa.

TABLE 1. Description of sites and observation dates during the study of pollination biology of Campsis radicans.

\begin{tabular}{|c|c|c|c|c|c|}
\hline \multirow{2}{*}{ Study site } & \multirow{2}{*}{ Symbol } & \multicolumn{2}{|c|}{ Observation days } & \multirow{2}{*}{ Neighbour flowers } & \multirow{2}{*}{ Fruit se } \\
\hline & & $2001^{1}$ & 2002 & & \\
\hline Campus of Warsaw Agricultural University & WA2 & 24-29 Jul & 26-29 Jul & $\begin{array}{l}\text { Trifolium spp., Medicago lupulina, Bellis perennis, } \\
\text { Buddleja davidii }\end{array}$ & $\mathrm{No}^{2}$ \\
\hline Kórnik Arboretum (Institute of Dendrology) & ID & - & 22-24 Jul & B. perennis, Trifolium repens & $\mathrm{No}^{3}$ \\
\hline Plant nursery in Józefosław & $\mathrm{JN}$ & 07 Aug & $31 \mathrm{Jul}$ & small herbaceous plants (e.g. B. perennis and T. repens) & $\mathrm{No}^{4}$ \\
\hline Warsaw University Botanic Garden & WA1 & 08 Aug & 29-30 Jul & $\begin{array}{l}\text { Bryonia alba (shoots intersperse with those } \\
\text { of } C \text {. radicans), Eupatorium cannabinum, } \\
\text { Cirsium oleraceum, Tanacetum vulgare }\end{array}$ & No \\
\hline Wrocław University Botanic Garden & WR & 01-04 Aug & $18-20 \mathrm{Jul}$ & Punica granatum, Canna spp., Hemerocallis spp. & Yes \\
\hline
\end{tabular}

\footnotetext{
${ }^{1}$ Night observations were conducted in WR (02-04 Aug) and WA1 (09 Aug).

2 J. Borowski, pers. inf.

${ }^{3}$ Arboretum employees, pers. inf.

4 J. Widaj, pers. inf.
} 
TABLE 2. Average number of insects visits to flowers of Campsis radicans during $12 \mathrm{~h}$ of observations and average pollen loads carried by an individual at different study sites. PL - average pollen load (no. of $C$. radicans pollen grains) carried by an individual insect shown in a relative scale: - no pollen; $t$ (trace, 1-10 pollen grains); * (11-50 pollen grains); ** (51-100 pollen grains); *** (101- $\infty$ pollen grains); $\mathrm{x}-\mathrm{no}$ data; $\mathrm{N}-$ number of visits (individuals captured and observed visiting flowers per $12 \mathrm{~h}$ of observations). For descriptions of study sites see Methods.

\begin{tabular}{|c|c|c|c|c|c|c|c|c|c|c|c|c|c|c|c|c|c|c|}
\hline \multirow{3}{*}{ Study site, year } & \multirow{2}{*}{\multicolumn{2}{|c|}{$\frac{\mathrm{ID}^{2}}{2002}$}} & \multicolumn{4}{|c|}{$\mathrm{JN}^{2}$} & \multicolumn{4}{|c|}{$\mathrm{WA}^{3}$} & \multicolumn{4}{|c|}{ WA $2^{4}$} & \multicolumn{4}{|c|}{$\mathrm{WR}^{4}$} \\
\hline & & & \multicolumn{2}{|c|}{2001} & \multicolumn{2}{|c|}{2002} & \multicolumn{2}{|c|}{2001} & \multicolumn{2}{|c|}{2002} & \multicolumn{2}{|c|}{2001} & \multicolumn{2}{|c|}{2002} & \multicolumn{2}{|c|}{2001} & \multicolumn{2}{|c|}{2002} \\
\hline & $\mathrm{N}$ & PL & $\mathrm{N}$ & PL & $\mathrm{N}$ & PL & $\mathrm{N}$ & PL & $\mathrm{N}$ & PL & $\mathrm{N}$ & PL & $\mathrm{N}$ & PL & $\mathrm{N}$ & PL & $\mathrm{N}$ & PL \\
\hline Apis mellifera $\mathrm{L}$. & 13.5 & $*$ & 15 & $* * *$ & 6 & $\mathrm{t}$ & 0 & $\mathrm{x}$ & 1 & $\mathrm{t}$ & 8.7 & $* * *$ & 12.3 & $* *$ & 10.3 & $* * *$ & 17.7 & $* * *$ \\
\hline Bombus pascuorum Scop. & 0.5 & $\mathrm{t}$ & 0 & $\mathrm{x}$ & 0 & $\mathrm{x}$ & 0 & $\mathrm{x}$ & 0 & $\mathrm{x}$ & 2.3 & $*$ & 1.3 & - & 0 & $\mathrm{x}$ & 0.3 & $*$ \\
\hline Paravespula 1 & 0 & $\mathrm{x}$ & 0 & $\mathrm{x}$ & 0 & $\mathrm{x}$ & 0 & $\mathrm{x}$ & 0 & $\mathrm{x}$ & 5 & $*$ & 0.7 & $\mathrm{x}$ & 0.3 & $\mathrm{x}$ & 0.3 & $\mathrm{x}$ \\
\hline other Hymenoptera & 0 & $\mathrm{x}$ & 1 & - & 0 & $\mathrm{x}$ & 3 & - & 0 & $\mathrm{x}$ & 0.7 & $\mathrm{t}$ & 0 & $\mathrm{x}$ & 0.7 & $\mathrm{t}$ & 0.7 & $\mathrm{t}$ \\
\hline Diptera & 0.5 & - & 0 & $\mathrm{x}$ & 0 & $\mathrm{x}$ & 0 & $\mathrm{x}$ & 0 & $\mathrm{x}$ & 0.7 & $* *$ & 0 & $\mathrm{x}$ & 2.3 & $\mathrm{t}$ & 0.7 & $\mathrm{t}$ \\
\hline Coccinella septempunctata (L.) & 0 & $\mathrm{x}$ & 0 & $\mathrm{x}$ & 0 & $\mathrm{x}$ & 0 & $\mathrm{x}$ & 0 & $\mathrm{x}$ & 0.3 & $\mathrm{t}$ & 0 & $\mathrm{x}$ & 0 & $\mathrm{x}$ & 0 & $\mathrm{x}$ \\
\hline
\end{tabular}

${ }^{1}$ Summed data for $P$. germanica (Fabr.) and P. vulgaris (L.)

${ }^{2}$ Observations carried for 2 days

${ }^{3}$ Observations carried for 1 day

${ }^{4}$ Observations carried for 3 days

\section{Hand-pollination}

Hand-pollination was conducted in 2002 at Warsaw University Botanic Garden on an individual vegetatively propagated from WA1. All open flowers form 10 inflorescences were removed. The remaining flower buds were covered with a fine mesh and stalks were wrapped with doublesided sticky tape, not to allow insects in. Maturing stigmas were pollinated with pollen from one stamen, which was collected either from flowers of the same plant or flowers of WA1 and WA2 plants.

\section{RESULTS}

\section{Insect visitors}

During $72 \mathrm{~h}$ of observation, seven insect taxa visited $C$. radicans flowers at different study sites (Table 2 ), these belonged to three insect orders: Coleoptera, Diptera and Hymenoptera. At all sites Hymenoptera prevailed (usually more than $95 \%$ of all visits, Fig. 1), insects from other orders were seen infrequently.

From among Hymenoptera the most frequent visitor was Apis mellifera (visits at all sites in both the seasons except
WA1 in 2001). In most sites (ID 2002, WA1 2002, WA2 2002, JN 2001 and 2002, WR 2002) it summed up to almost $100 \%$ of all visits, except WA2 in 2001, less than $50 \%$, and WR in 2001 - ca. 75\%. Bombus pasquorum was observed at ID (2002), WA2 (2001 and 2002) and at WR in 2002. Two species of Paravespula ( $P$. germanica and $P$. vulgaris) were observed at WA2 (2001 and 2002) and at WR (2001 and 2002). Also other unidentified Hymenoptera visited trumpet creeper flowers at WA1 (2001), WA2 (2001), JN (2001) and WR (both years). Diptera were noted in flowers of $C$. radicans at ID (2002), WA2 (2001), and WR (2001 and 2002). Coleoptera represented by Coccinella septempunctata were observed only once at WA2 (Table 2). At WA1 inflorescences of $C$. radicans were also visited by ants (Myrmecidae), which searched for copious nectar, however they did not enter the flower itself and fed exclusively on nectar exposed on a calyx. European earwig (Forficula auricularia) individuals were found in flowers of WA1 plant, they were not included among the visitors' analysis as they were not leaving or entering the flowers during census time.

Visitation frequency was low at all sites. Usually approx. 13-19 visits per day were observed (1-1.5 visits per census). The highest visit number (approx. 12-18 visits per

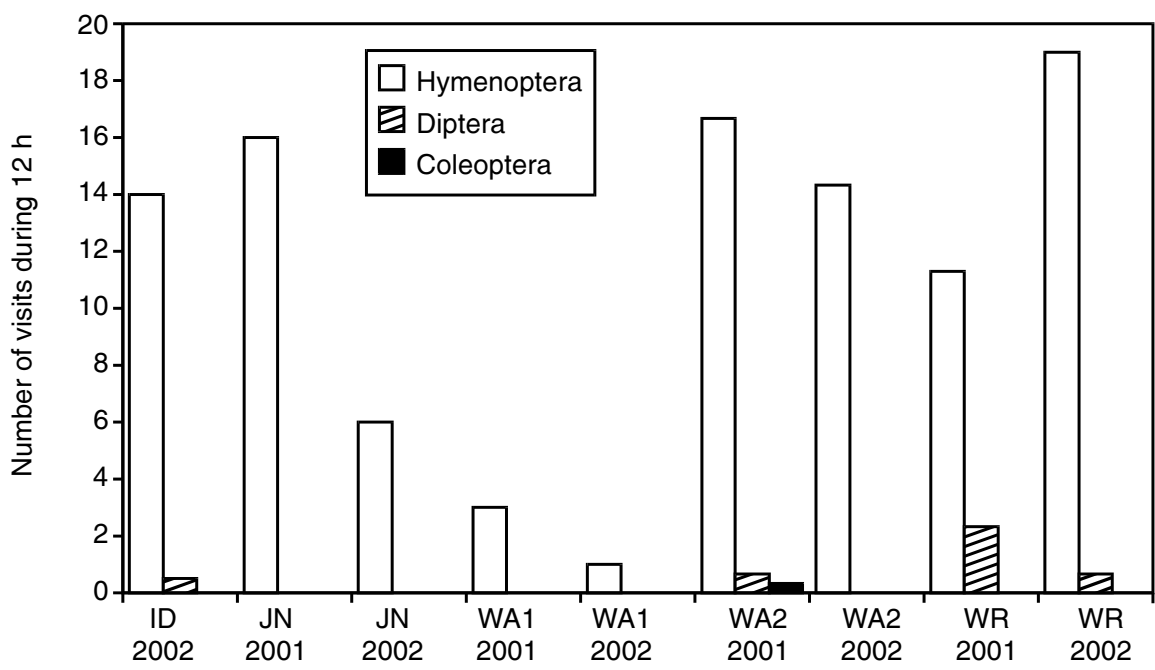

Fig. 1. Average number of insect visits to flowers of Campsis radicans during 12 hours of observations in years 2001 and 2002 (for site descriptions see Material and methods). 
day) were observed for A. mellifera (ID 2002, WA2 2002, JN 2001, WR 2002). Nocturnal observations were conducted at WA1 2001 and WR 2001 and no crepuscular insects were noticed in the flowers of $C$. radicans (Table 2).

At WA1 many flowers had damaged stamens and pistils (often anthers and stigmas were missing). In trumpet creeper flowers at WR holes in petals cut out by nectar robbers were recorded.

\section{Pollen loads}

Insects visiting flowers of $C$. radicans differed in their abilities in carrying pollen of trumpet creeper. Individuals of the same taxon in the same or other site would also carry pollen loads of various size. In general large pollen loads of $C$. radicans (more than 100 pollen grains) were carried only by individuals of $A$. mellifera, captured at WA2 (2001), JN (2001), and WR (2001 and 2002). Medium pollen loads (51-100 pollen grains) were also noted for $A$. mellifera (WA2 2002) and some Diptera (WA2 2001). Other insects carried less than 50 grains or no $C$. radicans pollen at all (Table 2).

\section{Pollinator importance}

The pollinators importance was calculated for all insect visitors at the given site according to the formula, shown in Material and methods. The most important pollinator at all sites was A. mellifera, in general it accounted for almost $100 \%$ of pollinations. Only in 2001 at WA2 two species of Paravespula, B. pasquorum and other insects accounted to $20 \%$. The presence of B. pasquorum was also notable at ID in 2002 (Fig. 2).

\section{Hand pollination}

Stigmas would close when the pollen was artificially applied. None of the flowers pollinated with self-pollen set fruit. Six of ten cross-pollinated flowers (60\%) set fruit, all matured and bore seeds.

\section{DISCUSSION}

C. radicans flowers are regarded as typically ornitogamous, they share most of characters connected with birdpollination syndrome: red pigmentation, copious and diluted nectar, lack of flower scent (Faegri and van der Pijl 1979; Proctor et al. 1996). However, this type of pollinator does not occur in Europe, where $C$. radicans is predominantly planted as ornamental climber. The present study shows that in Poland flowers of this species may be attractive also for several insect taxa, and hummingbird-pollinators may be substituted by common honeybees (A. mellife$\mathrm{ra}$ ), which were the most frequent and most efficient flower visitors at all study sites (Table 2, Fig. 2).

The high visitation ratio of bees to red flowers of $C$. radicans may seem unusual, as these insects are generally regarded red-blind (Faegri and van der Pijl 1979; Proctor et al. 1996). Red pigmentation is perceived as a clear signal to birds, sensitive to red, of a high nutritious value of such flowers, and is supposed to halt insect visitors that could deplete the flowers of nectar (Raven 1972). This explanation, however very attractive, is rather oversimplified. First there is a large evidence of different bees visiting and pollinating red bird-flowers, even for $C$. radicans described in its natural range as typical hummingbird-plant, bees constitute an important group of pollinators in disturbed habitats (Bertin 1982). Other red flowers, for example Ranunculus asiaticus, Anemone coronaria, Papaver rhoeas or Tulipa agenensis thrive in bird-free regions and are successfully pollinated by a guild of specialized beetles (Dafni et al. 1990). One of explanations is that there are very few truly red flowers. Although bees really have difficulties with recognizing monochromatic red (Chittka 1997) and their aversion to carotenoid-rich flowers was experimentally confirmed (Schemske and Bradshaw 1999), they can be successfully trained to red, and, what is more important, most of flowers that appear red to human eyes have a much

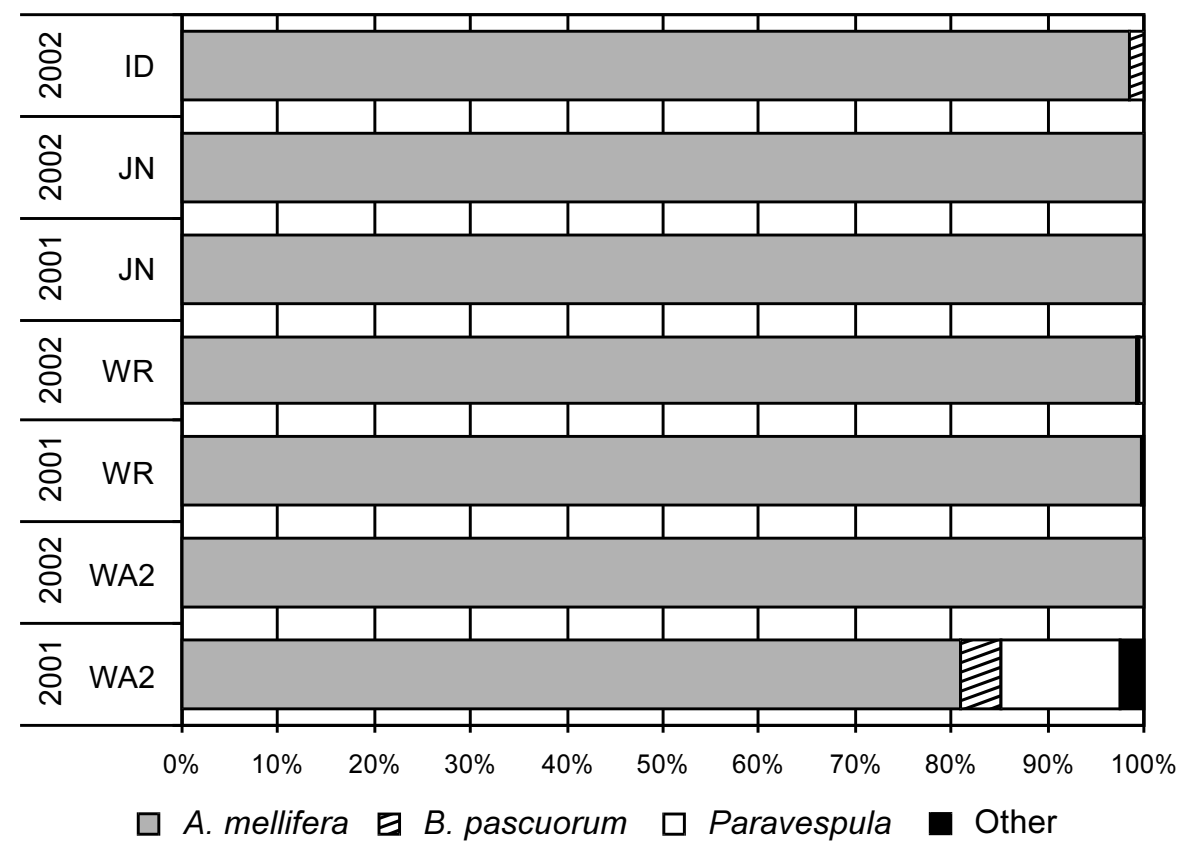

Fig. 2. Pollinator importance $(I)$ of insect taxa visiting Campsis radicans flowers in years 2001 and 2002 in four study sites (data for WA1 site was omitted due to scarce visitation rate). $I$ coefficient was calculated based on pollen loads and visit frequency (for details and site description see Material and methods). 
broader reflectance spectrum (Chittka and Waser 1997). That means they can be seen by bees, but they are far less conspicuous among the foliage than other colors (ornitogamous flowers are usually scentless). Birds do not seem to have any inner preferences for red (Raven 1972). Experiments with hummingbirds and mutant flowers of Mimulus show that there is indeed a very weak relationship between flower color and visitation rate. Birds in this study exhibited preferences towards flowers with high content of anthocyanin pigments rather than red carotenoids (Schemske and Bradshaw 1999). So the overall explanation of red bird-flowers is rather that they are visible to birds, which can learn to search for them all around the season (Sazima et al. 1995), and they are less visible to nectar-hungry bees, and that helps the plant to save floral resources for more efficient bird pollinators (Chittka et al. 2001).

Honeybees, although frequent in the present study on trumpet creeper flowers, are not ideally fit for its flowers. Pollen loads carried by these insects are very variable and in general not very high when compared to results of hummingbirds (approx. 400 pollen grains, Bertin 1982). In our study pollen loads ranged form less than 10 (ID 2002 and WA1 2002) to more than 350 pollen grains (WA2 2001 and WR 2001) (Table 2). According to Bertin (1982), $C$. radicans is primarily adapted for hummingbirds ( $A$. colubris) pollination, at least in the region examined by this author (Illinois and Missouri, USA), but in disturbed habitats where ruby-throated hummingbirds are absent, it can be adequately pollinated by honeybees (A. mellifera) and, to a lesser extent, bumblebees (Bombus spp.), which is also the case in the present study (Fig. 2). In this point, however, the question of plant cost-benefits balance arises.

Trumpet creeper ovary contains up to 1200 ovules and minimum 200 pollen grains are needed for fertilisation to occur, and some minimal number of ovules must be fertilised for fruit to develop (as much as 800 pollen grains deposit is needed for approx. $100 \%$ fruit production, and only over 4000 pollen grains give no further increase in seed number or mass). As honeybees deposit very little pollen during a single visit (44 grains on average), there is a need for multiply visits in order to set fruit, and even though the fruit set is low because of low visitation rate (Bertin 1982, 1990). This also may explain the very low seed set in Poland, as the highest number of visits recorded in the present study (Table 2) was similar to the data for USA (Bertin 1982).

Hummingbirds and bees differ in attitude towards pollen loads. The former utilise nectar and the latter both nectar and pollen, and individuals may specialize in pollen or nectar collection (Thomson et al. 2000), thus bees (especially A. mellifera) usually present high removal and low deposition rates as compared to other pollinators (Wilson and Thomson 1991; Lau and Galloway 2004).

Of course not all eaten pollen is wasted form plant's viewpoint as it contributes to pollinator's population fitness, but strategies increasing pollen deposition are favoured. Such a strategy might be pollen dosing achieved by gradual opening of anthers and through anthers opening just narrowly. Such strategy is usually prompted in bee-pollinated flowers, while hummingbird-pollinated flowers usually expose large amounts of pollen at the very beginning of anthesis. A change in the manner of pollen exposure might be adaptive for a plant when there are no bird po- llinators available (Thomson et al. 2000). In Poland, in our study of $C$. radicans, pollen was available for pollinators throughout the whole flowering period, in either sexual phase. No such phenomenon was observed at disturbed sites in USA, where honeybees and bumblebees removed all pollen within 2 hours form the beginning of anthesis (Bertin 1982).

Also changes in nectar volume and sugar concentration could potentially increase trumpet creeper's success in habitats where bee-pollination prevails. First, high nectar production is not necessary for attracting insects, and second, hummingbirds and honeybees prefer different nectar compositions. The case with the Bignoniaceae is even more ambiguous. Some authors (e.g. Galetto 1995) state that in numerous taxonomic groups, including Campsis family, nectar production and composition is related rather to flower architecture, than to nectar requirements of animal pollinators. It can be observed in nectary structure and nectar features of $C$. radicans, which are not typical for ornitophilous flowers. This may indicate a character no longer advantageous in terms of pollination success, similar for instance to the dark floret on the umbels of Daucus carota (Lamborn and Ollerton 2000), or some ancient 'fixation' of flower architecture constrained by phylogeny.

Honeybees are not the sole visitors to flowers of $C$. radicans in Poland (Table 2). Some other insects, although attracted by floral display, did not enter the flowers, but utilised the nectar, which is also secreted throughout the fleshy calyx (extranuptial nectaries, Galetto 1995). This may be disadvantageous for the plant as robbing causes energy loss, and the plant produces nectar which is used by insects, but pollination would not occur (Navarro 2001). This kind of insect behaviour was observed at all study sites, the most frequent robbers were wasps and ants. The former could be potential pollinators (Table 2, Fig. 2).

The question of flower robbing and its influence on overall plants fitness is not clear. Although it seems obvious that robbing should be detrimental for the plant, it eventually does not have to be so. Floral larceny may indirectly enhance female fitness by increased pollen dispersal distance, reduced self-pollen transfer (geitonogamy) and inbreeding through changes in pollinator behaviour associated with reduced nectar rewards (Maloof 2001; Irwin 2001). This however does not seem to be the case in trumpet creeper pollination in Poland because of high nectar production associated with adaptation to hummingbird pollination. It may happen that negative effects of robbing, for instance decreased visitation rate, may outweigh the advantage of decreased geitonogamy (Irwin 2001). For assessing this, detailed nectar production study would be needed, but in case of $C$. radicans in Poland, rather direct negative than indirect positive consequences of robbing are more likely to take place.

Apart of A. mellifera, the main flower visitor and pollinator of $C$. radicans in Poland, other insect visitors were scarce and of low importance (Table 2, Fig. 2). Even in case of common honeybee, its activity in some sites may be not sufficient to serve as reliable pollinator. For instance an individual of $C$. radicans at WA1, a place where $A$. mellifera is frequently encountered (Zych, pers. obser.), experienced almost no visits (Table 2). This might be due to various reasons. One of them might be the presence of other insects. At this site, for example, we observed European earwig 
(F. auricularia) and ants visiting the flowers of trumpet creeper. A. mellifera may avoid flowers where predator or dead honeybee body is present (Dukas 2001). Even if the bee does not mistake the earwig for the predator it may prefer not to visit already occupied flowers, and ants are known to discourage other flower visitors, not only insects (Beattie and Hughes 2002). Also lack of anthers (possibly eaten by $F$. auricularia) in some flowers at this site probably lowered the attractiveness of $C$. radicans. Another explanation of low visitation ratio may be the quality of surrounding vegetation. At WA1, the $C$. radicans plant was accompanied by attractive Bryonia alba, while in other sites the experimental plants grew in much less conspicuous vegetation (Table 1).

As shown in our study, honeybees may be important pollinators of introduced bird-pollinated $C$. radicans, it is however interesting, in terms of its potentially invasive character, to note the present low reproductive success of the plant - it rarely set seeds in Poland (Zych, pers. obser.). There are two possible reasons for this. First, trumpet creeper is adapted to milder climate conditions than those it meets in Poland. In many locations, especially in NE Poland, one-year old shoots are usually killed by frosts, and the plant behaves as perennial forb (Zych, pers. observ.). This means that the limiting factor for the generative reproduction to occur may be worse conditions for the flower, fruit and seedling development. The best seedling development in experimental setting was noted for seeds prechilled for 2 weeks and germinating in $35 / 25^{\circ} \mathrm{C}$ at the $12 \mathrm{~h}$ photoperiod. Nevertheless $10 \%$ of seeds were viable even after 4 months of prechilling. Seeds viability in field conditions is not known (Chachalis and Reddy 2000).

Second, $C$. radicans is said to be self incompatible (Bertin 1982), so the plant should need cross-pollen to produce fruit. The limiting factor would be therefore the availability of genetically different individuals in close proximity. This species is infrequent in Polish parks and gardens, and very few old specimens are known, these are usually located in botanic gardens, specialized arboreta or old nurseries (Seneta 1994; J. Dolatowski, pers. inf.). This should decrease the chance of fruit set to occur, especially when in some cases the effect of a pollen donor on a seed set of $C$. radicans is greater than effects of pollen load (Bertin 1990). Coupled with low pollen deposition by A. mellifera, these facts may greatly restrain the generative reproduction of the plant. For instance at WR, where few genetically different $C$. radicans individuals were present, seed set is observed every year, and our simple cross-pollination experiment proved that the plant, if cross-pollinated, can set viable seeds in other locations. Bertin and co-workers (Bertin and Sullivan 1988; Bertin et al. 1989; Bertin 1990) showed that $C$. radicans actually expresses the so-called cryptic self-fertility, which means it can be successfully pollinated even by mix of self and cross pollen. This, together with the information on the viability of seeds even in low temperatures (Chachalis and Reddy 2000), and spreading popularity of $C$. radicans as garden plant, may significantly increase the chances of this species to be naturalised especially in regions of milder climate (SW Poland).

In conclusion, our study shows that honeybee may well substitute the principal hummingbird pollinator of $C$. radicans in Europe, especially in habitats where this insect is abundant. This, coupled with the potentially invasive cha- racter of this species, should place trumpet creeper as an object of further careful examinations.

\section{ACKNOWLEDGEMENTS}

We are grateful to the staff of the following institutions and private companies: Faculty of Horticulture and Landscape Architecture - Warsaw Agricultural University, Institute of Dendrology at Kórnik, Joanna Widaj Plant Nursery, and Wrocław University Botanic Garden, for help and assistance during our field studies. We also thank Jakub Dolatowski, who provided us with information on $C$. radicans cultivation in Poland.

\section{LITERATURE CITED}

BEATTIE A.J., HUGHES L. 2002. Ant-plant interactions. In: Plant-Animal Interaction. C.M. Herrera and O. Pellmyr (eds). Blackwell, Oxford, pp. 236-247.

BERTIN R.I. 1982. Floral biology, hummingbird pollination and fruit production of trumpet creeper (Campsis radicans, Bignoniaceae). Am. J. Bot. 69: 122-134.

BERTIN R.I., SULLIVAN M. 1988. Pollen interference and cryptic self-fertility in Campsis radicans. Am. J. Bot. 75: 1140-1147.

BERTIN R.I., BARNES C., GUTTMAN S.I. 1989. Self-sterility and cryptic self-sterility in Campsis radicans (Bignoniaceae). Bot. Gazette 150: 397-403.

BERTIN R.I. 1990. Effects of pollination intensity in Campsis radicans. Am. J. Bot. 77: 178-187.

CHACHALIS D., REDDY K.N. 2000. Factors affecting Campsis radicans seed germination and seedling emergence. Weed Sci. 48: 212-216.

CHITTKA L. 1997. Bee colour vision is optimal for coding flower colours but flower colours are not optimal for being coded - why? Israel J. Plant Sci. 45: 115-127.

CHITTKA L., WASER N.M. 1997. Why red flowers are not invisible for bees. Israel J. Plant Sci. 45: 169-183.

CHITTKA L., SPAETHE J., SCHMIDT A., HICKELSBERGER A. 2001. Adaptation, constraint, and chance in the evolution of flower color and pollinator color vision. In: Cognitive ecology of pollination. Chittka L. and Thomson J.D. (eds). Cambridge University Press, pp. 106-126.

DAEHLER C.C. 1998. The taxonomic distribution of invasive angiosperm plants: ecological insights and comparison to agricultural weeds. Biol. Cons. 84: 167-180.

DAFNI A., BERNHARDT P., SHMIDA A., IVRI Y., GREENBAUM S., O’TOOLE C., LOSITO L. 1990. Red bowl-shaped flowers: convergence for beetle pollination in the Mediterranean region. Israel J. Bot. 39: 81-92.

DOWLER C.C. 1998. Weed survey - southern states broadleaf crops subsection. Proc. South. Weed Sci. Soc. 51: 299-313.

DUKAS R. 2001. Effects of perceived danger on flower choice by bees. Ecol. Letters 4: 327-333.

FAEGRI K., VAN DER PIJL L. 1979. The Principles of Pollination Ecology, $2^{\text {nd }}$ ed. Pergamon Press, Oxford.

GALETTO L. 1995. Nectary structure and nectar characteristics in some Bignoniaceae. Plant Syst. Evol. 196: 99-121.

GRACE J., NELSON M. 1981. Insects and their pollen loads at a hybrid Heracleum site. New Phytol. 87: 413-423.

IRWIN R.E. 2001. Impact of nectar robbing on estimates of pollen flow: conceptual predictions and empirical outcomes. Ecology 84: 485-495.

LAMBORN E., OLLERTON J. 2000. Experimental assessment of the functional morphology of inflorescence of Daucus caro- 
ta (Apiaceae): testing the 'fly catcher effect'. Funct. Ecol. 14: 445-454.

LAU J.A., GALLOWAY L.F. 2004. Effects of low-efficiency pollinators on plant fitness and floral trait evolution in Cатрапиla americana (Campanulaceae). Oecologia 141: 577-583.

LINDSEY A.H. 1984. Reproductive biology of Apiaceae. I. Floral visitors to Thaspium and Zizia and their importance in pollination. Am. J. Bot. 71: 375-387.

MALOOF J.E. 2001. The effects of a bumble bee nectar robber on plant reproductive success and pollinator behavior. Am. J. Bot. 88: 1960-1965.

NAVARRO L. 2001 Reproductive biology and effect of nectar robbing on fruit production in Macleania bullata (Ericaceae). Plant Ecol. 152: 59-65.

PELLMYR O. 2002. Pollination by animals. In: Plant-Animal Interaction. C.M. Herrera and O. Pellmyr (eds). Blackwell, Oxford, pp. 157-184.

POLISH NURSERYMEN ASSOCIATION (Związek Szkółkarzy Polskich) 2004. Internet Home Page: http://polskierosliny.pl/.

PROCTOR M., YEO P. AND LACK A. 1996. Natural History of Pollination. Harper Collins, London.

RAVEN P.H. 1972. Why are bird-visited flowers predominantly red? Evolution 26: 674.
REJMÁNEK M., RICHARDSON D.M. 1996. What attributes make some plant species more invasive? Ecology 77: 1655-1661 .

SAZIMA I., BUZATO S., SAZIMA M. 1995. The saw-billed hermit Ramphodon naevius and its flowers in southeastern Brazil. J. Ornithology 136: 195-206.

SCHEMSKE D.W., BRADSHAW H.D. Jr. 1999. Pollinator preference and the evolution of floral traits in monkeyflowers. Proc. Nat. Acad. Sci. 96: 11910-11915.

SENETA W. 1994. Angiosperm trees and shrubs. Wydawnictwo Naukowe PWN, Warszawa. (in Polish)

THOMSON J.D., WILSON P., VALENZUELA M., MALZONE M. 2000. Pollen presentation and pollination syndromes, with special reference to Penstemon. Plant Spec. Biol. 15: 11-29.

VINES R.A. 1960. Trees, shrubs and woody vines of the South West. University of Texas Press, Austin.

WILSON P., THOMSON J.D. 1991. Heterogeneity among floral visitors leads to discordance between removal and deposition of pollen. Ecology 72: 1503-1507.

ZYCH M. 2002. Pollination biology of Heracleum sphondylium L. (Apiaceae). The advantages of being white and compact. Acta Soc. Bot. Pol. 71: 163-170. 